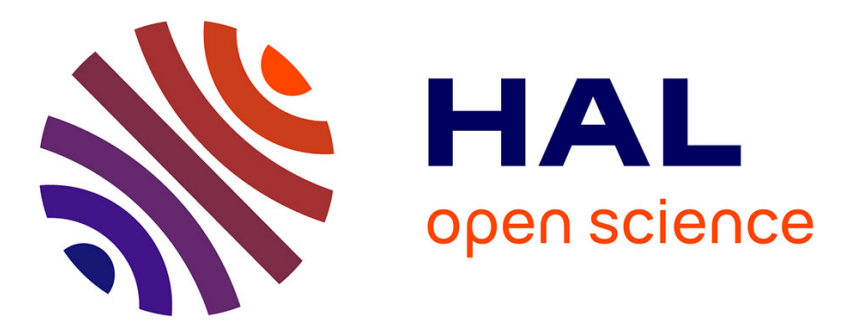

\title{
Benefits of early and prolonged fulvestrant treatment in 848 postmenopausal advanced breast cancer patients
}

\author{
Mathias Warm, Ronald Kates, Friedrich Overkamp, Anke Thomas, Nadia
}

Harbeck

\section{- To cite this version:}

Mathias Warm, Ronald Kates, Friedrich Overkamp, Anke Thomas, Nadia Harbeck. Benefits of early and prolonged fulvestrant treatment in 848 postmenopausal advanced breast cancer patients. Breast Cancer Research and Treatment, 2010, 125 (1), pp.127-136. 10.1007/s10549-010-1214-3 . hal00587266

\section{HAL Id: hal-00587266 \\ https://hal.science/hal-00587266}

Submitted on 20 Apr 2011

HAL is a multi-disciplinary open access archive for the deposit and dissemination of scientific research documents, whether they are published or not. The documents may come from teaching and research institutions in France or abroad, or from public or private research centers.
L'archive ouverte pluridisciplinaire HAL, est destinée au dépôt et à la diffusion de documents scientifiques de niveau recherche, publiés ou non, émanant des établissements d'enseignement et de recherche français ou étrangers, des laboratoires publics ou privés. 


\section{Benefits of early and prolonged fulvestrant treatment in 848 postmenopausal advanced breast cancer patients}

Mathias Warm ${ }^{1}$, Ronald Kates ${ }^{2}$, Friedrich Overkamp ${ }^{3}$, Anke Thomas ${ }^{4}$ and Nadia Harbeck $^{1}$

${ }^{1}$ Breast Center, University of Cologne; Germany;

${ }^{2}$ REK Consulting, Otterfing, Germany;

${ }^{3}$ Day Clinic for Hematology and Oncology, Recklinghausen, Germany;

${ }^{4}$ Department of Gynecology, University Berlin Charité, Berlin; Germany.

Address for correspondence: Mathias Warm, MD

Breast Center

University of Cologne

Kerpener Strasse 62, 50924 Cologne, Germany

Telefon: +49-221-478-8 6545

Fax: +49-221-478-8 6546

e-Mail: mathias.warm@uk-koeln.de

Running head: Benefits of early and prolonged fulvestrant treatment

Key Words: advanced breast cancer, fulvestrant, progesterone receptor, therapy

response

Presented in part at the Biennial European Breast Cancer Conference (EBCC), Berlin, Germany, 15-19 April 2008, the Annual Meeting of the American Society of Clinical Oncology (ASC0), Chicago, USA 30 May - 3 June 2008 and the conference of the German Society for Gynecology and Obstratrics (DGGG), Stuttgart, Germany 16-19 September 2008. 


\section{Abstract}

Purpose: Response to fulvestrant and survival in postmenopausal hormone-sensitive advanced breast cancer was investigated within a non-randomized, In-Practice Evaluation Program, with the aim of optimizing treatment decisions.

Methods: 848 patients (median age 64 years; 52\% co-morbidity; $78 \%$ prior palliative therapy; median 4 prior regimens) received monthly fulvestrant injections $(250 \mathrm{mg} / \mathrm{month})$ and were followed-up threemonthly for 9 months.

Results: Clinical benefit (PFS $\geq 24$ weeks) occurred in 532/848 (62.7\%); stable disease (SD) in 627/848 patients (74\%), including 62 complete and 177 partial responses. Best response was delayed in 115 patients. Estimated 9-month overall survival (OS) was 89\%; 9-month event-free survival (EFS) was $71 \%$. Indicators of disease aggressiveness affected response and survival, but number of fulvestrant cycles was the key OS and EFS determinant. Patients with SD at 3 months benefitted from continued fulvestrant. Excluding deaths, 7 serious adverse events occurred (none attributable to fulvestrant). No new or unexpected safety issues arose; $90 \%$ of patients and physicians rated fulvestrant tolerability as "very good" or "good".

Conclusions: In the largest prospective, fulvestrant-treated cohort to date, advanced breast cancer patients achieving SD or better after 3 months of treatment gained survival benefit by prolonging fulvestrant therapy - independent of disease and treatment history. 


\section{Introduction}

In advanced breast cancer, control of disease progression by endocrine rather than by cytotoxic agents induces fewer side effects and contributes to quality of life. However, in initially hormone-sensitive tumors, tamoxifen resistance [1-3] develops via estrogen-receptor (ER) agonistic effects, e.g. in bone or endometrium; increased tumor-cell sensitivity developing during long-term estrogen deprivation also promotes aromatase inhibitor $(\mathrm{Al})$ resistance [4].

Fulvestrant (Faslodex ${ }^{\circledR}$, AstraZeneca) is an ER-antagonist with no known agonistic effects $[5,6]$. Fulvestrant binds to the ER, blocks its function, causing rapid degradation of the ER, reduces subsequent progesterone receptor (PgR) expression [5], and inhibits ER-mediated gene transcription. This distinct mode of action results in a reduced risk of cross-resistance with other endocrine agents [7-12]. The two registration phase-III trials in postmenopausal patients with advanced breast cancer $(A B C)$ following antiestrogen therapy showed that response and progression-free survival (or time to progression, TTP) of fulvestrant and anastrozole were similar [13-15]. In ABC, fulvestrant was equally effective when compared to the steroidal Al exemestane after non-steroidal aromatase inhibitor therapy [16] and also equally effective to tamoxifen in patients without prior endocrine therapy [17]. In vitro, fulvestrant inhibits growth of ER-positive breast cancer cells [18], reduces ER levels [10], and inhibits estrogen-regulated proteins such as PgR, pS2, and Cathepsin D more strongly than tamoxifen [19]. This paper evaluates response to fulvestrant and survival (EFS and OS) in postmenopausal patients with advanced breast cancer receiving fulvestrant within an "In Practice Evaluation Program" (IPEP). The large $(n=848)$ and clinically representative collective provides sufficient statistical power to model "predictive" marker-treatment interactions and detect uncommon serious adverse events (SAE). The

IPEP framework also allows estimation of the frequency of delayed fulvestrant responses (beyond $2^{\text {nd }}$ examination/later than three months) and the probable consequences of prolonging/discontinuing therapy (based on course of response). These are central issues of clinical concern that have not been adequately addressed and which do not necessarily require a randomized study design.

\section{Methods}

\section{Patients and treatment}

Postmenopausal patients ( $n=848)$ with locally advanced or metastatic breast cancer received fulvestrant (Faslodex ${ }^{\circledR}$, AstraZeneca) $250 \mathrm{mg}$ via once-monthly intramuscular injections. The study was prospectively documented from 9/15/2004 (first patient in) until 3/28/2007 (last patient out); 278 office- 
Benefits of early and prolonged fulvestrant treatment

based gynecologists participated. All patients were classified hormone receptor positive; HER2 amplification (coded as IHC3+ or FISH+ vs. neg./unknown) was not a selection criterion [20].

Of the 848 included patients, $818(96.5 \%)$ had undergone primary surgery, $748(88.2 \%)$ had received systemic adjuvant therapy, and 760 (89.6\%) had received prior hormonal therapy. First examinations (beginning 1/29/2004) were documented retrospectively in 159 patients; in 69 of these cases, second examinations were also reported retrospectively. A total of 84 patients died before completing the study.

\section{Assessments and analyses}

Baseline (1) and follow-up examinations $(2,3,4)$ were scheduled at 3-month intervals for 9 months; within the IPEP, longer surveillance times also occurred. Response was categorized by individual physicians according to current guidelines (www.ago-online.de). AEs and SAEs were collected at each examination and coded according to MedDRA version 9.0. Multiple AEs occurring in a given patient within one organ system were counted once.

Baseline disease characteristics and detailed therapeutic history were documented; number and type of prior endocrine regimens, chemotherapy regimens, total (endocrine plus chemotherapy) regimens, and further information were computed from this data; numbers include adjuvant plus palliative therapies unless otherwise stated.

Concomitant medications counted as one line of treatment; interrupted regimens also counted only once. Binary (1/0) indicators were defined for "any past Al", "any past tamoxifen", and "past Al with no tamoxifen". Binary indicators were also defined describing presence or absence of metastatic disease at the following sites: bone, visceral, soft tissue, distant without bone, only bone, any distant, locally advanced and "other" (unknowns classified absent). The total number of fulvestrant injections received was denoted "fulvestrant cycles"; a binary indicator was defined using the media number of cycles (>7 vs. $\leq 7$ cycles, representing 6 months of treatment versus shorter).

\section{Statistical analyses}

Endpoints were overall survival, event-free survival, and best response to fulvestrant. Duration of overall survival (OS) and event-free survival (EFS) were defined from the time of first fulvestrant injection. To calculate the event-free survival interval, "events" refer to premature termination due to $\mathrm{SAE}$, disease progression (PD), or death. Patients terminating for other reasons were considered rightcensored. Response proportions are given with respect to the entire study population ( $n=848)$. 
Benefits of early and prolonged fulvestrant treatment

The impact of various factors on EFS and OS was determined using Cox proportional hazards models (stepwise forward unless otherwise stated); OS was estimated using the product-limit method (log-rank test). Weibull distributions were also fitted to estimate median OS and EFS when most patients were censored before median survival was reached in Kaplan-Meier estimates.

Chi-square or Fisher's exact test were used to analyze relationships between categorical variables. The T-test (or the Mann-Whitney U-test) was used to assess relationships between binary and metric variables. Spearman (rank) correlations are denoted $R_{S}$. Responses were coded on an ordinal scale: $0=$ unknown, 1=PD, 2=stable disease (SD), 3=partial response (PR), 4=complete response $(C R)$. Binary (1/0) efficacy indicators were defined for "remission" [PR or CR vs unknown, PD or SD] and "benefit" [PR, CR or SD vs PD or unknown]. (The term CB is reserved for benefit persisting $\geq 24$ weeks). Odds ratios (OR) characterizing the impact of various factors on binary indicators were estimated by univariate and multiple logistic regression analyses. Area under receiver operating characteristic $(\mathrm{ROC})$ curves was also used to characterize the impact of these factors.

Metric variables - age, body mass index (BMI), and total number of fulvestrant cycles, were entered in logistic (or Cox) regression analyses as fractional population rank. Corresponding OR and hazard ratios (HR) were interpreted accordingly.

SAS and SPSS were used to perform these statistical analyses; 95\% confidence intervals were reported; all p-values are two-sided.

\section{Results}

\section{Patient characteristics and treatment}

Baseline characteristics are shown in Table 1. Number of prior chemotherapy lines (but not endocrine therapy) was associated with the presence vs absence of metastases: visceral (2.2 lines vs. 1.5 lines, $p<0.001)$, soft tissue (2.1 lines vs. 1.7 lines, $p=0.003$ ), and other distant metastases (1.8 vs. $1.6, p$ $<0.001)$. Median number of fulvestrant cycles was $7\left(4-9 ; 25^{\text {th }}-75^{\text {th }}\right.$ percentile). Benefit was observed in $627 / 848$ patients $(74 \%)$, including $62(7.3 \%)$ complete and $177(21 \%)$ partial responses.

\section{Initial predictors of response}

Chemotherapy pretreatment was unfavorably associated with best response to fulvestrant $(p=0.017$; Fisher), with higher progression (18.6\% : 11.8\%) and lower CR (7.2\% : 13.7\%) rates; patients with prior endocrine therapy had higher response $(P R+C R)$ rates than those without $(34.5 \%: 17.1 \% ; p=0.002)$. 
Benefits of early and prolonged fulvestrant treatment

A response during last treatment significantly predicted response to fulvestrant: $O R=3.01(2.15-4.23$, $p<0.001) ; R_{S}=0.3(p<0.001)($ Table 2$)$.

\section{Course of response}

Best response was delayed (beyond $2^{\text {nd }}$ examination) in 115 patients (see Table 2). Remarkably, $18 \%$ $(84 / 459)$ of patients with stabilization at $2^{\text {nd }}$ examination subsequently achieved partial or even complete remission; of those with $>7$ cycles (about $64 \%$ ), $26 \%$ improved, compared to $4.8 \%$ of the others $(p<0.001)$.

\section{Association between number of fulvestrant cycles and response}

Number of fulvestrant cycles were strongly associated with benefit [PR, CR, SD], as one would expect. Treating response as an ordinal variable, number of fulvestrant cycles also correlated with response $\left(R_{S}=0.42, p<0.001\right)$. Dichotomizing the treatment variable ( $>7$ vs. $<=7$ cycles) yielded $\log (O R)=3.8$ (3.1-4.5); fractionally ranking fulvestrant cycles yielded $\log (O R)=9.8$ (8.4-11.2), implying, e.g., OR $>100$ for "benefit" in a patient receiving nine fulvestrant cycles compared to four. An ROC curve for "benefit" as a function of cycles had AUC $=0.93$ (0.90-0.95).

Obviously, this association partially reflects the fact that patients with favorable outcome will be more likely to continue fulvestrant. However, it is truly noteworthy that "fulvestrant cycles" strongly predicted subsequent remission $[\log (O R)=4.1(2.9-5.4)]$ in the key subgroup $(n=459)$ of patients with $S D$ at $2^{\text {nd }}$ examination.

\section{Overall survival}

Overall, 84 deaths were recorded, 66 within 9 months. Estimated 9-month OS (including censoring) was $89.1 \%$ (86.5\%-91.8\%); median OS was estimated at 26 months (Weibull fit). OS was strongly associated with best response to fulvestrant [HR=0.3 (0.2-0.45) per ordinal level] (Figure 1).

In univariate models, higher number of fulvestrant cycles, fewer previous therapy lines, better response to last therapy, and higher BMI were favorable for OS; locally advanced disease, visceral or exclusively bone metastases were unfavorable (Table 3, left).

In multivariate analysis, fulvestrant cycles dominated all other factors in the whole collective (Table 3 , top right) and in subgroups (SD at second examination, $C B$ by second examination). Patients with SD at $2^{\text {nd }}$ examination who received $>7$ fulvestrant cycles had an HR of $0.120(0.054-0.267)$ for OS, with visceral metastases having an unfavorable effect on outcome.

As the number of fulvestrant cycles was determined not by randomization, but by course of response, Table 3 (bottom right) also presents multivariate analyses of OS, restricted to factors known initially 
Benefits of early and prolonged fulvestrant treatment

(i.e., excluding fulvestrant cycles). All significant univariate factors were independent multivariate predictors for OS in this analysis.

\section{Disease progression and event-free survival}

Overall, 532/848 (uncensored) patients had CB, i.e., were known to be progression-free for $\geq 24$ weeks; 167 progressed (one with subsequent response) or died within 24 weeks. Events were recorded in 265/848 patients. Median EFS was 12 months (Weibull and Kaplan-Meier estimators).

In addition to number of fulvestrant cycles, earlier therapy line and negative PgR status appeared to be independently favorable for EFS (Table 4). There were no significant associations between EFS and BMI, locally advanced disease, bone metastasis (only), line of endocrine therapy, line of Al therapy, soft tissue metastasis, breast cancer survival, HER2 status or ER status. Since PgR status entered the multivariate model despite lacking univariate significance, receptor-treatment interactions were tested for: an interaction between $\mathrm{PgR}$ status and number of fulvestrant cycles was detected $(\mathrm{HR}=0.22)$. Noting $\mathrm{HR}=2.85$ for $\mathrm{PgR}$ status and $\mathrm{HR}=0.06$ for number of fulvestrant cycles, and comparing with the other multivariate EFS model, the implication is that while EFS generally improved with prolonged fulvestrant treatment, PgR-positive patients benefited most. The PgR-positive and PgR-negative groups were well-balanced in terms of the number of fulvestrant cycles received; qualitatively similar findings were observed grouping "unknown" with positive PgR status. No interactions were detected involving either ER or HER2 status.

In the subgroup of patients with SD by $2^{\text {nd }}$ examination ( 3 months), patients receiving $>7$ cycles had a HR of 0.479 (0.294 - 0.782) for EFS, with visceral metastases having an unfavorable impact.

\section{Safety and Tolerability}

Seven SAEs were recorded, none of which were judged to be attributable to fulvestrant. Two SAEs resulted in subsequent death (pulmonary embolism, pneumonia); one non-fatal stroke and one nonfatal heart attack also occurred. Table 5 summarizes all non-serious AEs occurring among the 848 patients included in this study. No new or unexpected safety issues arose. Of the 84 patients who died during this study, heart failure/insufficiency was explicitly cited in the deaths of six patients; one of these six patients had suffered a previous AE attributed to fulvestrant (urticaria). In all, nine of the 84 patients who died had a documented $\mathrm{AE}$; of these, the only $\mathrm{AE}$ attributed to fulvestrant was the aforementioned urticaria. Breast cancer was the reported cause of 69/84 deaths; of the remaining 15 deaths, the reported causes were as follows: organ failure (heart/cardiovascular, kidney, liver, lungs/pneumonia, multiple) and general (general worsening, cachexia, unknown); there was no evidence that any of the deaths were attributable to fulvestrant. 
Benefits of early and prolonged fulvestrant treatment

Treatment tolerability was assessed by patients and physicians for both the patient's last breast cancer therapy and for fulvestrant (Table 6). Patient and physician ratings were strongly correlated $\left(R_{S}>0.87\right.$; $\mathrm{p}<0.001$ ), with slightly higher physician-rated tolerability. Very good tolerability was reported in $41.4 \%$ to $47.5 \%$ of patients receiving fulvestrant $(46.7 \%$ to $51.6 \%$ of physicians) compared to $20.0 \%$ for last therapy (18.0\% of physicians). The percentages of patients (or physicians) reporting "insufficient" tolerability of fulvestrant was $\leq 1.5 \%$ and the percentages reporting "good" or "very good" exceeded $90 \%$.

Almost half of all patients reported an improvement in tolerability of fulvestrant compared with their last therapy (Table 7). Tolerability at $2^{\text {nd }}$ examination was also positively associated with EFS: Combining the "good" and "very good" categories, the HR associated with each degree of improvement (e.g., "insufficient" $\rightarrow$ "satisfactory" etc.) was $0.570(0.425-0.765, \mathrm{P}<0.001)$. This association may be partly attributable to the correlation $\left(R_{S}=0.14, P<.001\right)$ between tolerability (ordinal scale) and number of fulvestrant cycles; in the metastatic setting, patient-reported tolerability may also reflect palliative benefits and thus quality of life.

\section{Discussion}

Due to its efficacy even after failure of other endocrine agents, fulvestrant represents a valuable treatment option for patients with advanced breast cancer whose disease is not immediately lifethreatening [7-12]. Previous results [21] demonstrated the importance of allowing sufficient time (>2 months) for evaluating response to fulvestrant - for example, a patient may still respond despite intermittent rises in CA15.3. In phase III trials, time to response was 3.1 months for Fulvestrant (range 0.9 - 33.1 months) [22]. The present single-arm study comprises the largest available data set for studying fulvestrant in advanced breast cancer, providing more power for subgroup and multivariate interaction analyses.

Analysis of the degree to which response and survival are positively influenced by fulvestrant therapy requires careful consideration of the present study design: Since this is an observational study, a "feedback" process is possible, i.e., duration of fulvestrant therapy is influenced by response, so that a cause-and-effect or dose-response relationship cannot be inferred. The "best" responders (PR or CR within 3 months) tended to prolong fulvestrant treatment, receive more cycles, and benefit most. Patients without benefit by 3 months tended to discontinue fulvestrant and almost never improved even if they had subsequent fulvestrant treatment. 
Benefits of early and prolonged fulvestrant treatment

However, in "intermediate" responders - the 459 patients with SD within three months, but not yet partial or complete response - the decision to prolong fulvestrant therapy was split $(64 \%$ received $>7$ cycles). It truly noteworthy that in this subgroup, number of fulvestrant cycles (i.e., continuation of fulvestrant after SD at 3 months) was strongly associated with subsequent response $(O R \approx 60)$. For example, a remission occurred in approximately one-quarter of intermediate responders receiving $>7$ fulvestrant cycles, compared with about one-twentieth of those receiving $\leq 7$ cycles. Moreover, intermediate responders receiving $>7$ cycles had a substantial advantage in OS and EFS. The survival benefit of receiving more fulvestrant cycles was almost as strong in patients with (only) SD by 3 months as it was in the overall population. Summarizing, in the subgroup of "intermediate responders," the inference of a positive dose-response relationship does appear to be the most likely explanation of the data.

Considering the substantial pre-treatment and other patient characteristics, the estimated 9-month OS of $89 \%$ (median OS $\approx 26$ months) compares favorably with the 24 -month median OS considered typical for patients metastatic breast cancer. Estimated median EFS was 12 months - which also gives a conservative estimate of median TTP. These estimates underline the benefits of fulvestrant for patients with hormone-sensitive, metastatic breast cancer.

Seven SAEs were recorded, none of which were attributable to fulvestrant; and no new or unexpected safety issues arose. An advantage of the intramuscular mode of administration of fulvestrant is that compliance is not an issue. Over $90 \%$ of both patients and physicians rated fulvestrant tolerability as "very good" or "good" throughout the study. Moreover, almost half of all patients reported improved tolerability of fulvestrant compared with their last therapy. It is also noteworthy that tolerability was predictive of improved EFS. This relationship could be explained by the likelihood of receiving more cycles, which was strongly associated with improved EFS and OS.

A patient's response to fulvestrant reflects multiple dynamically interacting and competing biological processes regulating cancer cell growth in that individual. Previous trials have shown that fulvestrant is active in patients with visceral metastases [23-26]. However, direct indicators and surrogates for disease aggressiveness would still be expected to exert some negative influence on response and survival. Thus, presence of visceral metastases had negative impact on OS and EFS (in all patients and in the subgroup with SD at 3 months). The (positive) association of "fewer lines of previous therapy" with EFS and OS and the (negative) association of "previous chemotherapy" with fulvestrant response could also be attributable to their association with disease aggressiveness, as evidenced by 
Benefits of early and prolonged fulvestrant treatment

the correlation of visceral metastases with chemotherapy. In contrast, "best response to previous therapy" was a strong predictor of response to fulvestrant, EFS and OS, but was not strongly associated with disease aggressiveness markers. This observation is consistent with results from the EFECT trial $[16,27]$. Further research is required to permit a better understanding of the relationship between response to previous therapy and response to fulvestrant.

Here, for the first time, a predictive interaction between $\mathrm{PgR}$ status and number of fulvestrant cycles was identified in the multivariate analysis of EFS. A previous report [20] based on a study of 155 metastatic breast cancer patients did not find an interaction of this type. However, the effect size observed here would not have been significant in a 155-patient study, because the confidence interval for $\log (\mathrm{HR})$ would have been about 2.3 times wider, thus overlapping zero; hence the apparent difference could be attributable to increased power. Interpretation of the predictive interaction requires consideration of the multivariate model (Table 4) as a whole: In patients receiving fewer fulvestrant cycles, EFS was worse in PgR-positive than in PgR-negative patients (controlling for line of therapy and presence of visceral metastases). In the whole collective, EFS improved with number of fulvestrant cycles, but the observed benefit was greater in PgR-positive patients - more than enough to compensate for the "disadvantage" of PgR-positivity.

Considering the biological role of $\mathrm{PgR}$ regulation in fulvestrant efficacy, the possible increased benefit in patients with positive PgR status could provide an interesting hypothesis for future controlled studies (with centralized receptor determination). In view of the association of molecular types with clinical outcomes [28], we note that the predictive value of presence or absence of PgR could also hint at a fundamental difference between luminal A vs. luminal B type tumors even in the metastatic context.

While factors and surrogates for disease aggressiveness (e.g., visceral metastases, previous chemotherapy, etc.) were negatively associated with response, patients responding at all (stabilization or better) by three months had substantial survival benefit from continued fulvestrant treatment. This statement applies to patients with previous chemotherapy, aromatase inhibitor therapy (whether pretreated by tamoxifen or not). Notwithstanding, our data suggest that it would be prudent to plan therapy strategies in advanced and metastatic breast cancer by providing fulvestrant as an additional endocrine therapy line to patients at a sufficiently early stage so as to improve the chances of responding. This strategy is also supported by recent health economic data [29]. 
Benefits of early and prolonged fulvestrant treatment

In this IPEP, fulvestrant therapy was usually terminated in patients with PD at three months and continued in patients with remission (CR or PR) at this time. Current clinical practice is supported by our data in these patient groups. However, in patients achieving "only" SD by three months (who constituted the majority) fulvestrant therapy was terminated in over $30 \%$ of cases. The present results suggest that continuation of fulvestrant therapy in all patients achieving SD at three months is likely to benefit these patients in terms of (possibly delayed) remission, quality of life, and survival. It would be valuable to validate these findings in the ongoing clinical fulvestrant trials[30, 31]. Moreover, recent trial results with a higher dose of fulvestrant $(500 \mathrm{mg})$ suggest that the observed effects in responders may even be greater when fulvestrant is administered at the higher dose [32, 33].

\section{Acknowledgement}

The authors would like to thank Silke Zaun MD, PhD from AstraZeneca for supplying the patient data, for very useful discussions, and for editing support. Dawn Batty, PhD from Complete Medical Communications provided editing support, funded by AstraZeneca. Approval of the final manuscript rested with the authors, who are responsible for all scientific content. 


\section{References}

1. Milano A, Dal Lago L, Sotiriou C et al (2006) What clinicians need to know about antioestrogen resistance in breast cancer therapy. Eur J Cancer 42:2692-2705

2. Adamo V, lorfida M, Montalto E et al (2007) Overview and new strategies in metastatic breast cancer (MBC) for treatment of tamoxifen-resistant patients. Ann Oncol 18:vi53-57

3. Kurokawa H, Arteaga CL (2003) ErbB (HER) receptors can abrogate antiestrogen action in human breast cancer by multiple signaling mechanism. Clin Cancer Res 9:511S-515S

4. Howell A (2005) The future of fulvestrant (“Faslodex"). Cancer Treat Rev 31:S26-33

5. Wakeling AE, Dukes M, Bowler J (1991) A potent specific pure antiestrogen with clinical potential. Cancer Res 51:3867-3873

6. Wakeling AE (2000) Similarities and distinctions in the mode of action of different classes of antiestrogens. Endocr Relat Cancer 7:17-28

7. Fawell SE, White R, Hoare S et al (1990) Inhibition of estrogen receptor-DNA binding by the "pure" antiestrogen ICI 164,384 appears to be mediated by impaired receptor dimerization. Proc Natl Acad Sci U S A. 87:6883-6887

8. Dauvois S, White R, Parker MG (1993) The antiestrogen ICl 182780 disrupts estrogen receptor nucleocytoplasmic shuttling. J Cell Sci 106:1377-1388

9. Nicholson RI, Gee JM, Manning DL et al (1995) Responses to pure antiestrogens (ICI 164384, ICI 182780) in estrogen-sensitive and -resistant experimental and clinical breast cancer. Ann N Y Acad Sci 761:148-163

10. McClelland RA, Gee JM, Francis AB et al (1996) Short-term effects of pure anti-oestrogen ICI 182780 treatment on oestrogen receptor, epidermal growth factor receptor and transforming growth factor-alpha protein expression in human breast cancer. Eur J Cancer 32A:413-416

11. Pietras RJ, Marquez DC, Chen HW et al (2003) Improved antitumor therapy with Herceptin and Faslodex for dual targeting of HER-2 and estrogen receptor signalling pathways in human breast cancers with overexpression of HER-2/neu gene. Breast Cancer Res Treat 82(Suppl. 1):S12

12. Howell A, DeFriend DJ, Robertson JF et al (1996) Pharmacokinetics, pharmacological and antitumour effects of the specific anti-oestrogen ICl 182780 in women with advanced breast cancer. $\mathrm{Br}$ J Cancer 74:300-308

13. Osborne CK, Pippen J, Jones SE et al (2002) Double-blind, randomized trial comparing the efficacy and tolerability of fulvestrant versus anastrozole in postmenopausal women with advanced 
breast cancer progressing on prior endocrine therapy: Results of a North American trial. J Clin Oncol 20:3386-3395

14. Howell A, Robertson JF, Quaresma Albano J et al (2002) Fulvestrant, formerly ICl 182,780, is as effective as anastrozole in postmenopausal women with advanced breast cancer progressing after prior endocrine treatment. J Clin Oncol 20:3396-3403

15. Robertson JF, Osborne CK, Howell A et al (2003) Fulvestrant versus anastrozole for the treatment of advanced breast cancinoma in postmenopausal women: a prospective combined analysis of two multicenter trials. Cancer 98:229-238

16. Chia S, Gradishar W, Mauriac L et al (2008) Double-blind, randomized placebo controlled trial of fulvestrant compared with exemestane after prior nonsteroidal aromatase inhibitor therapy in postmenopausal women with hormone receptor-positive, advanced breast cancer: results from EFECT. J Clin Oncol 26:1664-1670

17. Howell A, Robertson JF, Abram P et al (2004) Comparison of fulvestrant versus tamoxifen for the treatment of advanced breast cancer in postmenopausal women previously untreated with endocrine therapy: a multinational, double-blind, randomized trial. J Clin Oncol 22:1605-1613

18. Hu XF, Veroni M, De Luise M et al (1993) Circumvention of tamoxifen resistance by the pure antiestrogen ICI 182,780. Int J Cancer 55:873-876

19. Freddie CT, Christensen GL, Lykkesfeldt AE (2004) A new MCF-7 breast cancer cell line resistant to the arzoxifene metabolite desmethylarzoxifene. Mol Cell Endocrinol 220:97-107

20. Bartsch R, Wenzel C, Altorjai $G$ et al (2007) Her2 and progesterone receptor status are not predictive of response to fulvestrant treatment. Clin Cancer Res 13:4435-4439

21. Robertson JF, A. Agrawal A, Gutteridge E et al (2006) Correlation of CA15.3 levels with clinical response in advanced breast cancer (ABC) patients receiving fulvestrant. J Clin Oncol 24:18S (abstr 641)

22. Dodwell D, Pippen J (2006) Time to response: Comparison of fulvestrant and oral endocrine agents. Clin Breast Cancer 7:244-247

23. Mauriac L, Pippen JE, Quaresma Albano J et al (2003) Fulvestrant (Faslodex) versus anastrozole for the second-line treatment of advanced breast cancer in subgroups of postmenopausal women with visceral and non-visceral metastases: combined results from two multicentre trials. Eur $\mathrm{J}$ Cancer 39:1228-1233 
Benefits of early and prolonged fulvestrant treatment

24. Bartsch R, Mlineritsch B, Gnant M et al (2009) The Austrian fulvestrant registry: results from a prospective observation of fulvestrant in postmenopausal patients with metastatic breast cancer. Breast Cancer Res Treat 115:373-380

25. Mlineritsch B, Psenak O, Mayer P et al (2007) Fulvestrant ('Faslodex') in heavily pretreated postmenopausal patients with advanced breast cancer: single centre clinical experience from the compassionate use programme. Breast Cancer Res Treat 106:105-112

26. Mauriac L, Romieu G, Bines J (2009) Activity of fulvestrant versus exemestane in advanced breast cancer patients with or without visceral metastases: data from the EFECT trial. Breast Cancer Res Treat 117:69-75

27. Chia S, Gradishar W (2008) Fulvestrant: expanding the endocrine treatment options for patients with hormone receptor-positive advanced breast cancer. Breast 17:S16-21

28. Sorlie T, Tibshirani R, Parker J et al (2003) Repeated observation of breast tumor subtypes in independent gene expression data sets. Proc Natl Acad Sci U S A.100(14):8418-8423

29. Lux MP, Hartmann M, Jackisch C et al (2009) Cost-utility analysis for advanced breast cancer therapy in Germany: results of the fulvestrant sequencing model. Breast Cancer Res Treat $117: 305-317$

30. Freedman O, Amir E, Dranitsaris G et al (2009) Predicting benefit from fulvestrant in pretreated metastatic breast cancer patients. Breast Cancer Res Treat 118:377-383

31. Mello CA, Chinen LT, da Silva SC et al (2010) Prolonged time to progression with fulvestrant for metastatic breast cancer. Med Oncol. doi:10.1007/s12032-010-9469-4

32. Robertson JF, Llombart-Cussac A, Rolski J et al (2009) Activity of fulvestrant $500 \mathrm{mg}$ versus anastrozole $1 \mathrm{mg}$ as first-line treatment for advanced breast cancer: results from the FIRST study. J Clin Oncol 27:4530-4535

33. Di Leo A, Jerusalem G, Petruzelka L et al (2010) Results of the CONFIRM Phase III Trial Comparing Fulvestrant $250 \mathrm{mg}$ With Fulvestrant $500 \mathrm{mg}$ in Postmenopausal Women With Estrogen Receptor-Positive Advanced Breast Cancer. J Clin Oncol. doi:10.1200/JCO.2010.28.8415 


\section{Tables}

Table 1 Patient baseline characteristics: a) Distributions of metric variables; b) Tumor characteristics: metastases and hormone receptors

a)

\begin{tabular}{|l|c|c|c|}
\hline Metric variables & \multicolumn{3}{|c|}{ Total } \\
\hline & Mean & SD & N valid \\
\hline Age [years] & 64.4 & 10.4 & 836 \\
\hline Body Mass Index [kg/m^2] & 26.4 & 4.6 & 824 \\
\hline $\begin{array}{l}\text { Survival (from original breast cancer diagnosis to } \\
\text { study begin) [months] }\end{array}$ & 93.4 & 68.4 & 788 \\
\hline Duration of response to last therapy [months] & 18.3 & 19.7 & 575 \\
\hline Number of prior therapy regimens & 4.0 & 2.1 & 848 \\
\hline
\end{tabular}

b)

\begin{tabular}{|c|c|c|}
\hline \multirow{2}{*}{\begin{tabular}{|l} 
Sites of \\
metastases \\
Category
\end{tabular}} & \multicolumn{2}{|c|}{ Patients, n (\%) } \\
\hline & Present & Absent or unknown \\
\hline Local advanced & $324(38.2)$ & $524(61.8)$ \\
\hline Any distant & $796(93.9)$ & $52(6.1)$ \\
\hline Visceral & $321(37.9)$ & $527(62.1)$ \\
\hline Bone & $486(57.3)$ & $362(42.7)$ \\
\hline Soft tissue & $161(19.0)$ & $687(81.0)$ \\
\hline $\begin{array}{l}\text { Other distant } \\
\text { metastases }\end{array}$ & $133(15.7)$ & $715(84.3)$ \\
\hline Only bone & $215(25.4)$ & $633(74.6)$ \\
\hline Distant without bone & $252(29.7)$ & $596(70.3)$ \\
\hline \multicolumn{2}{|c|}{ Receptor status } & Patients, n (\%) \\
\hline \multirow[t]{3}{*}{ ER } & \multirow{3}{*}{$\begin{array}{l}\text { Negative } \\
\text { Unknown } \\
\text { Positive }\end{array}$} & $27(3.2)$ \\
\hline & & $23(2.7)$ \\
\hline & & $798(94.1)$ \\
\hline \multirow[t]{3}{*}{$\mathrm{PgR}$} & \multirow{3}{*}{$\begin{array}{l}\text { Negative } \\
\text { Unknown } \\
\text { Positive }\end{array}$} & $116(13.7)$ \\
\hline & & $40(4.7)$ \\
\hline & & $692(81.6)$ \\
\hline \multirow[t]{4}{*}{ HER2 } & \multirow{4}{*}{$\begin{array}{c}\text { Negative } \\
\text { Unknown } \\
\mathrm{FISH}+ \\
\mathrm{IHC}+++\end{array}$} & $345(40.7)$ \\
\hline & & $333(39.3)$ \\
\hline & & $56(6.6)$ \\
\hline & & $114(13.4)$ \\
\hline
\end{tabular}

$\mathrm{ER}=$ estrogen receptor; $\mathrm{PgR}=$ progesterone receptor; HER2 = human epidermal growth factor receptor 2 
Benefits of early and prolonged fulvestrant treatment

Table 2 Best response (BR) to fulvestrant vs BR to last therapy, BR at second examination or BR at 3rd examination

\begin{tabular}{|c|c|c|c|c|c|c|c|}
\hline & & \multicolumn{5}{|c|}{ Best response to fulvestrant } & \multirow[b]{2}{*}{ Tota } \\
\hline & & unknown & PD & SD & PR & CR & \\
\hline \multirow{5}{*}{$\begin{array}{l}\text { Best response } \\
\text { to last therapy }\end{array}$} & Unknown & 36 & 18 & 59 & 24 & 13 & 150 \\
\hline & PD & 6 & 11 & 22 & 6 & 1 & 46 \\
\hline & SD & 32 & 63 & 193 & 62 & 10 & 360 \\
\hline & PR & 22 & 23 & 95 & 65 & 13 & 218 \\
\hline & CR & 4 & 6 & 19 & 20 & 25 & 74 \\
\hline \multirow{5}{*}{$\begin{array}{l}\text { Response } \\
\text { to fulvestrant } \\
\left(2^{\text {nd }}\right. \\
\text { examination) }\end{array}$} & Unknown & 100 & 10 & 13 & 3 & 0 & 126 \\
\hline & PD & 0 & 111 & 0 & 1 & 0 & 112 \\
\hline & SD & 0 & 0 & 375 & 73 & 11 & 459 \\
\hline & PR & 0 & 0 & 0 & 100 & 14 & 114 \\
\hline & CR & 0 & 0 & 0 & 0 & 37 & 37 \\
\hline \multirow{5}{*}{$\begin{array}{l}\text { Best response } \\
\text { to fulvestrant } \\
\text { (up to } 3^{\text {rd }} \\
\text { examination) }\end{array}$} & Unknown & 100 & 2 & 2 & 0 & 0 & 104 \\
\hline & PD & 0 & 119 & 0 & 0 & 0 & 119 \\
\hline & SD & 0 & 0 & 386 & 24 & 3 & 413 \\
\hline & PR & 0 & 0 & 0 & 153 & 5 & 158 \\
\hline & CR & 0 & 0 & 0 & 0 & 54 & 54 \\
\hline \multicolumn{2}{|l|}{ Totals } & 100 & 121 & 388 & 177 & 62 & 848 \\
\hline
\end{tabular}

$\mathrm{PD}=$ disease progression $; \mathrm{SD}=$ stable disease $; \mathrm{PR}=$ partial response $; \mathrm{CR}=$ complete response 
Table 3 Proportional hazard models for OS. Entered but not significant: age, antihormonal therapy line, bone metastases, soft tissue metastases, time since breast cancer diagnosis, HER2, PgR, ER, interactions of fulvestrant cycles with PgR, ER, HER2. Left: univarate. Right: two multivariate models (including/excluding fulvestrant)

\begin{tabular}{|c|c|c|c|c|c|c|}
\hline OS & \multicolumn{3}{|c|}{ Univariate } & \multicolumn{3}{|c|}{$\begin{array}{c}\text { Multivariate } \\
\text { (fulvestrant \& factors entered) }\end{array}$} \\
\hline Factors & $P$ & $\mathrm{HR}(95 \% \mathrm{Cl})$ & In (HR) & $P$ & $\mathrm{HR}(95 \% \mathrm{Cl})$ & In (HR) \\
\hline \multirow{2}{*}{$\begin{array}{c}\text { Fulvestrant: } \\
\text { number of cycles } \\
\text { (fractionally ranked) }\end{array}$} & \multirow[t]{2}{*}{$<0.001$} & \multirow[t]{2}{*}{$.002(.001-.006)$} & \multirow[t]{2}{*}{-6.25} & $<0.001$ & $.002(.001-.005)$ & -6.41 \\
\hline & & & & \multicolumn{3}{|c|}{$\begin{array}{c}\text { Multivariate } \\
\text { (excluding fulvestrant; other } \\
\text { factors entered) }\end{array}$} \\
\hline $\begin{array}{l}\text { Response to last therapy } \\
\text { (scaled } 1 \text { to } 4 \text { ) }\end{array}$ & $<0.001$ & $0.71(0.60-0.85)$ & -0.34 & 0.002 & $0.73(0.60-0.89)$ & -0.31 \\
\hline BMI (fractionally ranked) & 0.017 & $0.39(0.18-0.85)$ & -0.94 & 0.021 & $0.39(0.18-0.87)$ & -0.94 \\
\hline Line of therapy (number) & $<0.001$ & $1.17(1.07-1.28)$ & 0.16 & 0.023 & $1.12(1.01-1.23)$ & 0.11 \\
\hline $\begin{array}{l}\text { Locally advanced disease } \\
\text { (present vs absent) }\end{array}$ & 0.007 & $1.63(1.14-2.32)$ & 0.49 & 0.007 & $1.68(1.15-2.45)$ & 0.52 \\
\hline $\begin{array}{l}\text { Bone metastases only (yes } \\
\text { vs no) }\end{array}$ & 0.010 & $1.79(1.15-2.81)$ & 0.58 & 0.015 & $1.79(1.12-2.87)$ & 0.58 \\
\hline $\begin{array}{l}\text { Visceral metastases (present } \\
\text { vs absent) }\end{array}$ & 0.018 & $1.68(1.09-2.57)$ & 0.52 & 0.042 & $1.63(1.02-2.60)$ & 0.49 \\
\hline
\end{tabular}

$\mathrm{HR}=$ estimated hazard ratio; $\mathrm{In}=$ natural logarithm 
Table 4 Upper left: Univariate hazard ratios of factors for EFS in forward stepwise Cox regression; upper right: multivariate model excluding fulvestrant. Lower left: multivariate EFS model including fulvestrant; Lower right: multivariate receptor interaction model by backward stepwise Cox regression

\begin{tabular}{|c|c|c|c|c|c|c|}
\hline EFS & \multicolumn{3}{|c|}{ Univariate } & \multicolumn{3}{|c|}{$\begin{array}{c}\text { Multivariate } \\
\text { (excluding fulvestrant; } \\
\text { other factors entered) }\end{array}$} \\
\hline Factors & $P$ & $\mathrm{HR}(95 \% \mathrm{Cl})$ & In (HR) & $\mathrm{P}$ & $\mathrm{HR}(95 \% \mathrm{Cl})$ & $\ln (\mathrm{HR})$ \\
\hline $\begin{array}{l}\text { Fulvestrant therapy: } \\
\text { number of cycles } \\
\text { (fractionally ranked) }\end{array}$ & $<0.001$ & $\begin{array}{c}0.015 \\
(0.009-0.025)\end{array}$ & -4.20 & \multicolumn{3}{|c|}{ not entered } \\
\hline Line of therapy (number) & $<0.001$ & $1.14(1.08-1.20)$ & 0.13 & $<0.001$ & $1.11(1.05-1.17)$ & 0.10 \\
\hline $\begin{array}{c}\text { Line of palliative hormonal } \\
\text { therapy }\end{array}$ & 0.003 & $1.18(1.06-1.31)$ & 0.16 & \multicolumn{3}{|c|}{ not significant } \\
\hline Palliative Al therapy & 0.047 & $1.30(1.00-1.69)$ & 0.27 & \multicolumn{3}{|c|}{ not significant } \\
\hline $\begin{array}{l}\text { Response to last therapy } \\
\text { (scaled } 1 \text { to } 4 \text { ) }\end{array}$ & 0.002 & $0.85(0.77-0.94)$ & -0.16 & 0.002 & $0.84(0.75-0.94)$ & -0.18 \\
\hline $\begin{array}{l}\text { Visceral metastases } \\
\text { (present vs absent) }\end{array}$ & 0.001 & $1.52(1.19-1.94)$ & 0.42 & 0.013 & $1.41(1.08-1.84)$ & 0.34 \\
\hline $\begin{array}{l}\text { Bone metastases } \\
\text { (present vs absent) }\end{array}$ & 0.014 & $1.38(1.07-1.78)$ & 0.32 & & not significant & \\
\hline $\begin{array}{l}\text { Binary PgR status } \\
\text { (positive vs negative or } \\
\text { unknown) }\end{array}$ & \multicolumn{3}{|c|}{ not significant } & \multicolumn{3}{|c|}{ not significant } \\
\hline EFS & \multicolumn{3}{|c|}{$\begin{array}{c}\text { Multivariate } \\
\text { (fulvestrant \& factors entered) }\end{array}$} & \multicolumn{3}{|c|}{$\begin{array}{c}\text { Multivariate } \\
\text { (fulvestrant, factors \& receptor } \\
\text { interactions entered) }\end{array}$} \\
\hline Factors & $\mathrm{P}$ & $\mathrm{HR}(95 \% \mathrm{Cl})$ & $\ln (\mathrm{HR})$ & $P$ & $\mathrm{HR}(95 \% \mathrm{Cl})$ & $\ln (\mathrm{HR})$ \\
\hline $\begin{array}{l}\text { Fulvestrant therapy: } \\
\text { number of cycles } \\
\text { (fractionally ranked) }\end{array}$ & $<0.001$ & $0.02(0.01-0.03)$ & -4.18 & $<0.001$ & $0.06(0.02-0.20)$ & -2.90 \\
\hline Line of therapy (number) & 0.012 & $1.07(1.02-1.13)$ & 0.07 & 0.040 & $1.06(1.00-1.12)$ & 0.06 \\
\hline $\begin{array}{l}\text { Visceral metastases } \\
\text { (present vs absent) }\end{array}$ & \multicolumn{3}{|c|}{ not significant } & 0.080 & $1.27(0.97-1.66)$ & 0.24 \\
\hline $\begin{array}{l}\text { Binary PgR status } \\
\text { (positive vs negative or } \\
\text { unknown) }\end{array}$ & 0.007 & $1.70(1.16-2.50)$ & 0.53 & 0.002 & $2.85(1.49-5.46)$ & 1.05 \\
\hline $\begin{array}{c}\text { Interaction: binary PgR } \\
\text { status * fractionally ranked } \\
\text { fulvestrant cycles }\end{array}$ & \multicolumn{3}{|c|}{ not entered } & 0.040 & $0.22(0.05-0.94)$ & -1.49 \\
\hline
\end{tabular}


Table 5 Occurrence of non-serious adverse events during fulvestrant treatment including those reported at study end $(n=848)$. PD was reported in 86 patients as an AE (none of which were reported as being due to fulvestrant)

\section{Primary system organ class}

General disorders and administration site conditions

Gastrointestinal disorders

Musculoskeletal and connective tissue disorders

Skin and subcutaneous tissue disorders

Respiratory, thoracic and mediastinal disorders

Nervous system disorders

Vascular disorders

Investigational procedures

Blood and lymphatic system disorders

Infections

Psychiatric disorders

Hepatobiliary disorders

Metabolism and nutrition disorders

Injuries and procedural complications

Cardiac disorders

Eye disorders

Renal and urinary disorders

Surgical and medical procedures

Immune system disorders

Reproductive system and breast disorders

Total
Patients affected by $A E$

52

30

22

12

18

16

17

6

10

12

8

11

10

2

7

2

4

3

1

1

244 subset judged "due to fulvestrant"

4

3

1

4

0

1

7

2

0

1

4

1

0

0

0

2

0

0

0

1

31 
Benefits of early and prolonged fulvestrant treatment

Table 6 Tolerability of previous therapy and fulvestrant as reported by patients and physicians

\begin{tabular}{|l|c|c|c|c|c|c|c|c|}
\hline \multicolumn{1}{|c|}{ Tolerability } & \multicolumn{2}{|c|}{ Last therapy } & \multicolumn{6}{c|}{ Fulvestrant } \\
\hline & & \multicolumn{2}{|c|}{ Examination 2 } & \multicolumn{2}{|c|}{ Examination 3 } & \multicolumn{2}{c|}{ Examination 4 } \\
\cline { 2 - 10 } & Patient & Physician & Patient & Physician & Patient & Physician & Patient & Physician \\
\hline Very good & $20.0 \%$ & $18.0 \%$ & $41.4 \%$ & $46.7 \%$ & $43.1 \%$ & $47.3 \%$ & $47.5 \%$ & $51.6 \%$ \\
\cline { 2 - 10 } \\
Good
\end{tabular}


Table 7 Improvement of tolerability reported by patients from last therapy to fulvestrant at $2^{\text {nd }}$ examination $(n=730)$

\begin{tabular}{|c|c|c|}
\hline Degree of Improvement & Improvement & $\begin{array}{c}\text { Patients, } \\
\text { number (\%) }\end{array}$ \\
\hline-3 & Very good $\rightarrow$ Insufficient & $1(0.1)$ \\
-2 & Very good $\rightarrow$ Satisfactory & $5(0.7)$ \\
-1 & Very good $\rightarrow$ Good & $56(7.7)$ \\
0 & Very good $\rightarrow$ Very good & $310(42.5)$ \\
1 & Good $\rightarrow$ Very good & $217(29.7)$ \\
2 & Satisfactory $\rightarrow$ Very good & $107(14.7)$ \\
3 & Insufficient $\rightarrow$ Very good & $34(4.7)$ \\
\hline
\end{tabular}

\section{Figure}

Figure 1 OS by best response to fulvestrant; 9-month OS in each subgroup was estimated using the product limit method ( $p<0.001)$ : response unknown (50\%), PD (76\%), SD (92\%) PR (98\%), CR $(100 \%)$.

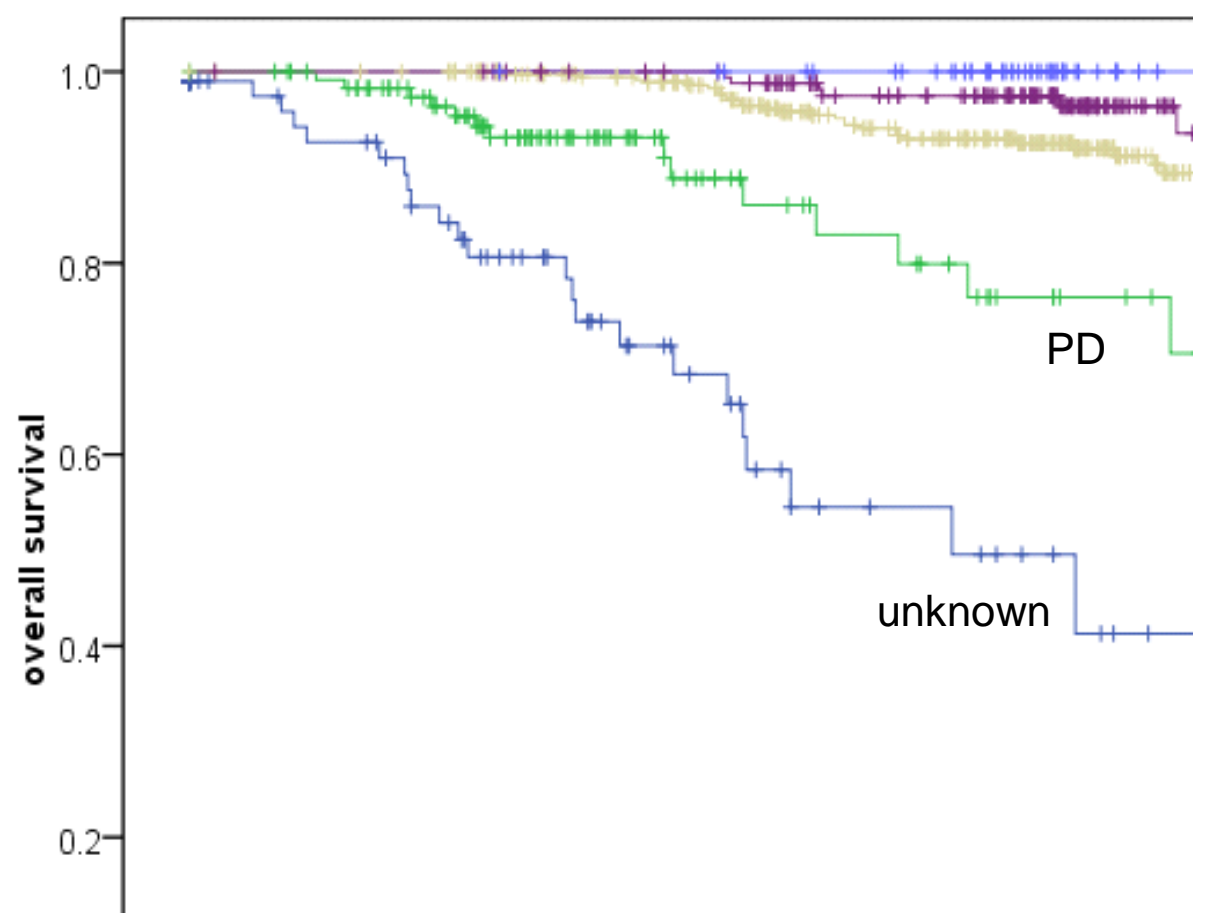

